\title{
Mono-segment Fixation Method Versus Short- segment Fixation Methods, In Treatment Of Mono- segmental Lumbar Tuberculosis; Using Titanium Mesh Cage With Interbody Fusion: Retrospective Cohort Study.
}

Hongqi Zhang

Central South University Xiangya School of Medicine

Daudi Romani Manini ( $\nabla$ daudiromani@yahoo.co.uk)

Central South University Xiangya School of Medicine

Yuxiang Wang

Central South University Xiangya School of Medicine

Research article

Keywords: ,

Posted Date: October 30th, 2019

DOI: https://doi.org/10.21203/rs.2.16596/v1

License: (1) (i) This work is licensed under a Creative Commons Attribution 4.0 International License.

Read Full License 


\section{Abstract}

Background $\otimes 1 / 3$ rd-2/3rd of the remaining vertebral height can hold and withstand the standard pedicle screws; some surgeons have adopted affected vertebral fixation to avoid the complications of both long and short segment fixation during surgical correction of lumbar tuberculosis (TB). This study aimed to compare efficacy of mono-segment-fixation versus the short-segment fixation methods with the use of titanium mesh-cage (TMCs) and interbody fusion in the treatment of mono-segmental lumbar spinal TB via single stage posterior-only approach.

Methods $₫$ A retrospective review was done among 34 lumbar spinal TB patients. These patients underwent debridement, interbody fusion with (TMCs) by either Mono-segment fixation or short-segment fixation methods. Eighteen patients underwent mono-segment fixation method, group (A). While 16 patients underwent short-segment fixation method, group (B). Fusion, deformity correction, and decompression were done within the affected segment in group (A), while for group (B) fusion extended one level above and below the affected vertebrae. Operation time, intra-operative blood loss, degree of deformity correction and neurological functions were analyzed.

Results: Comparing group (A) vs (B), average operation time in minutes (mins) for group A was 144.2 \pm 16.5 , group $B$ was $170.3 \pm 25.0(P=0.001)$. Average intraoperative blood loss in milliliter $(\mathrm{mls})$ was $502.8 \pm 151.9$ for group $(A)$ and $742.5 \pm 143.2$ for group $(B)(p \otimes 0.05)$. The mean cobb's angle between group A versus group $B$; preoperative was $23.8 \pm 6.50$ vs $22.2 \pm 9.20(p=0.6)$, immediate post operatively was $8.0 \pm 3.50$ vs $8.3 \pm 5.70(p=0.847)$ and at final follow-up was $8.9 \pm 3.10$ vs $9.2 \pm 5.90(p=0.866)$ respectively. Correction rate between group $(A)$ vs group $(B)$ was $15.7 \pm 3.80$ vs $13.9 \pm 5.50(p=0.285)$ and loss of correction was $1.2 \pm 0.70$ vs $1.1 \pm 0.7(p=0.817)$ respectively. No significant differences in neurological recovery between the two groups were founds.

Conclusion: Under precise conditions: mono-segment fixation method, debridement, interbody fusion with TMCs, and posterior instrumentation can effectively reconstruct the spine, maintain stability and correct kyphosis deformity similar to short-segment fixation method. Also, it can relieve pain and improve neurological symptoms. When used in combination with anti-TB chemotherapy in the treatment of monosegmental lumbar TB via a single-stage posterior-only approach.

\section{Introduction}

According to the WHO report, "globally in 2017, there were an estimated 10.0 million incident cases of TB (range, 9.0-11.1 million) ${ }^{2}$, equivalent to 133 cases (range, 120-148) per 100000 population". Spinal TB is the most common form of extrapulmonary TB. Spinal TB accounts for approximately $50 \%$ of all cases of musculoskeletal tuberculosis. Spinal TB has increased because of the increased human immunodeficiency virus (HIV) epidemic and drug resistance. Lumbar tuberculosis is very threatening because it may lead to bone destruction, deformity, and paraplegia $(1,2)$. 
Despite ant-tuberculous chemotherapy being the golden standard for treatment of spinal tuberculosis, its demerits are the failure to prevent the progression of deformity and decompression. Surgical treatment is needed for patients with preexisting or residual deformity, severe or progressive neurologic dysfunction, spinal instability, and extensive paravertebral and epidural abscesses $(3,4)$.

Currently, the available surgical techniques for lumbar TB include anterior spinal fusion, anterior-posterior spinal fusion, posterior spinal fusion alone and posterior fusion followed by anterior spinal fusion $(5,6)$. However, orthopedic surgeons have different views regarding the range of fixation. For instance, some prefer long-segment fixation (includes two or more normal motor units superior and inferior to the diseased segment), while others favor short-segment fixation (includes a single normal motor unit superior and inferior to the diseased segment). The merits of the two fixation methods include regaining the normal structure of the spine and preserving the correction. Reported demerits include a decrease in mobility and loss of function of the normal motor unit, which accelerates adjacent-segmental disease (ASD). Moreover, long segments fixation results in more concentrated stress and exert greater forces on adjacent segments. These effects accelerate adjacent-segment degeneration, leading to lower back pain, pseudarthrosis and implant failure (7-9).

Since $1 / 3-2 / 3$ of the residual vertebral height can hold and withstand the normal pedicle screws, some surgeons have adopted affected vertebral fixation in order to avoid the complications of both long and short segment fixation. In the affected vertebral fixation (also known as mono-segment fixation), debridement is carried out within the diseased motor units only. The screws are inserted into the pedicle of the diseased vertebrae only and the graft materials are placed between the diseased vertebrae. Debridement decompression and deformity correction are done within the interval of the diseased vertebrae (10-12).

However, there has been no detailed information on the use of the mono-segment fixation method, debridement, interbody fusion, with TMCs in the treatment of mono-segmental lumbar TB (via single stage posterior-only approach). Therefore, the aim of this retrospective study is to compare between mono-segment fixation method versus short-segment fixation method using TMCs with interbody fusion in the treatment of mono-segmental lumbar spinal TB via single stage posterior-only approach.

\section{Methods}

\section{Study design;}

retrospective cohort study

\section{Setting;}

This study was conducted in the Spine department of Xiangya hospital of central South University. Data were retrieved from the medical records. The study protocol was approved by the Ethics Committee of the 
Xiangya first Hospital of Central South University.

The study included 34 patients with lumbar TB who had undergone either mono-segment fixation or short-segment fixation in spine department of Xiangya first hospital of Central South University from January 2012 to December 2016.

\section{Participants}

Inclusion criteria (1) patients with the infection involving only a single motor unit. (2) patients with vertebral destruction range between $1 / 3-2 / 3$ of the original vertebral body height as determined by threedimensional CT. (3) patients with lumbar kyphosis cobb angle $>10^{\circ}$. (4) patients with age above 18 years. Exclusion criteria; (1) patients with active pulmonary or extrapulmonary TB and cancer (2) Patients with kyphosis cobb angle $\left(>60^{\circ}\right)$. (3) Patients with osteoporosis. (4) patients with multisegmented infections. (5) patients with other spinal abnormalities.

\section{Bias}

Bias in this study were assessed in two levels; at study level and outcome level. Study level bias assessment involved assessing for selection biases and detection biases. On the outcome level, information bias and attrition bias were assessed.

At study level, selection biases were mitigated by two ways. Firstly, Cases were selected from Hospital's database for patients diagnosed with TB to ensure reliability. This is anticipated to minimize detection biases. Finally, all participants were selected from the same population of participants attending Xiangya Hospital, so that exposures will be more or less, similar.

At outcome level, two authors were involved in recording data into the spreadsheet. This is anticipated to reduce typing errors. To minimize attrition biases, only participants regularly visiting the Xiangya Hospital were eligible for inclusion. To minimize reporting biases, STROBE tool (Strengthening Reporting of Observational Epidemiological Studies) customized for cohort studies, were used in the write-up of this research work.

\section{Surgical indications;}

(1) Neurological deficit due to spinal cord or cauda equina compression. (2) Lumbar instability and kyphosis. (3) patients with either abscess, sequestrum, or long discharging sinus tract. (4) patients with severe pain caused by the diseased lesions.

In all patient's complete debridement, bone grafting with titanium mesh cage, decompression, and deformity correction were done within the diseased segments through posterior only approach. Patients were divided into two groups ( $A$ and $B$ ) according to fixation techniques. Group A had a mono-segment 
fixation ( $n=18)$, in which posterior fixation was carried out within the diseased motor units. Group B had the short-segment fixation $(n=16)$, in which posterior fixation included the diseased vertebrae together with one normal motor unit superior and inferior to the diseased vertebrae. Patients' characteristics and preoperative variables are shown in Table 1.

\section{Preoperative management}

On admission, patients were placed on complete bed rest. Preoperative anti-tuberculosis drugs HREZ, (isoniazid (5 mg/kg), rifampicin (10 mg/kg), ethambutol (15 mg/kg), and pyrazinamide $(25 \mathrm{mg} / \mathrm{kg}$ ) were administered 14 to 28 days before the operation. Coexisting diseases were routinely controlled. Blood pressure less than $140 / 90 \mathrm{mmHg}$, random blood sugar less than $11.0 \mathrm{mmol} / \mathrm{L}$, good appetite, and weight gain were preferred. Antiosteoporosis drugs were administrated in older patients before surgery. Liver and Renal functions were monitored, and their damage was treated promptly. surgery was carried out after the patients' condition had improved.

\section{Operation technique for group A}

After administration of general anesthesia midline posterior approach was applied with patient placed in prone position. Extra periosteal dissection was made subperiosteally along midline incision to display the posterior spinal elements. The laminae, facet joints, and transverse process were displayed. The exploration exposed one vertebra more above and below the diseased segment. Pedicle screws were placed with the help of C-arm guided fluoroscopy into the diseased vertebrae only. Routine pedicle screws were placed in the diseased vertebrae if the remained heights of the diseased vertebrae were more than one third. laminectomy was done at both side on the diseased part and the cord was decompressed under clear visualization. A pre-bent temporary rod was applied on contralateral side of the focus and stabilized to avoid spinal cord injury caused by spinal instability during decompression and focal debridement. Laminectomy, facetectomy, transversectomy, excision of spinous processes and other posterior elements on the working side (opposite to the side with the pre-bent rod) were done to display the lateral wall of the pedicle. The nerve roots of the diseased lumbar level were moderately retracted to providespace for the surgical procedure of anterior decompression or debridement, as described by Rajasekaran et al (13). All diseased and necrotic disc and bony tissue were excised until the fresh bleeding bone was seen. Both paravertebral and epidural abscesses were evacuated, and debridement was accurately performed until all pus and infectious debris were finished. Debridement near the medulla spinalis was done with a great care, curettes and rongeurs were used very slowly. The same process was repeated on the other side of the lesion if necessarily needed. The rods were firmly secured, and kyphosis was gradually corrected with the aid of compression and stretching of internal instrumentation. A preprocessed shaped TMCs filled with autogenous bone (harvested from the spinous process and lamina) or allograft spongy bone were placed in the bone trough to reconstruct the spine. A cross linker was added to enhance stability in each patient as shown in figure 1 below. 
"Fig 1. A 49 years old male with lumbar spinal tuberculosis lesion at I2/I3 who underwent mono-segment fixation. a: Preoperative anteroposterior view; b: preoperative lateral view; c: postoperative anteroposterior view; d: postoperative lateral view.

\section{Operation technique for group B}

The surgical approach and all steps for group B were the same as those of group A. They only differed by the placement of the pedicle screws. Pedicle screws were placed on the diseased vertebra and on normal motor unit above and below the diseased vertebra, one on each side. A crosslinker was also used for all patients to enhance stability. Posterolateral bone grafting TMCs were the same as those of the monosegmental fixation group. As shown in figure 2 below

"Fig 2. A 54 years old male with lumbar spinal tuberculosis lesion at /3/14 who underwent short-segment fixation. a: Preoperative anteroposterior view; b: preoperative lateral view; c: postoperative anteroposterior view; d: postoperative lateral view.

Streptomycin $1.0 \mathrm{~g}$ and isoniazid $0.2 \mathrm{~g}$ were given locally on the diseased site before wound closure. A drain was inserted and well secured, incisions were closed. Excised specimens were sent for bacterial culture and other pathological diagnosis.

\section{Postoperative care}

The drainage tube was removed after 3 days. Except when there was an extensive paraspinal abscess it was left fixed until the volume of drainage was less than $30 \mathrm{ml} / 24 \mathrm{~h}$. Patients continued with oral anti-TB chemotherapy postoperatively. Pyrazinamide was withdrawn at 6 months. Patients kept on taking HREZ chemotherapy for 9 - to 12-months. Patients were encouraged to ambulate with a brace 6-8 weeks postoperative. Patients were limited to non-weight-bearing activities until there was radiographic evidence of bone fusion. For the first 6 months after surgery, patients attended our outpatient clinic each month. While, from 6 months to 3 years, the patients attended our outpatient clinic once a year. During visit, medical check-up and physical examination were taken. Ten-point Visual analog scale score VAS, Oswestry disability index score ODI and Frankel grade were recorded. We measured erythrocyte sedimentation rate ESR, C-reactive protein CRP, liver function test and renal function test. A decision to stop anti-TB drugs was made based on normal examination results and healing of the lesion (which was determined by $\mathrm{X}$-rays, $\mathrm{CT}$, magnet resonance imaging (MRI), and ultrasonography).

Cobb's angle was used to judge the correction of the lumbar spine in the sagittal plane. Cobb's angle was measured by drawing lines along the superior and inferior endplate of the diseased segment in the lateral radiograph. The radiolucent halo zone around the implant of more than $1 \mathrm{~mm}$ on lateral X-ray film or CT, was regarded as implant failure. Bone fusion was defined as no radiolucent lines covering more than half of either implant, a slight movement of $3 \mathrm{~mm}$ or less, $5^{0}$ or less on flexion-extension lateral radiographs, and continuous trabecular bone growth between the vertebral bodies. TB healing was identified by: no 
pain or tenderness on the diseased site, no cold abscess or discharging sinus, continuous normal range of both ESR and CRP, and complete bone fusion as seen from radiographic imaging.

\section{Statistical analysis}

Statistical analysis was done using IBM SPSS statistic 21 version software. Age, follow-up time, VAS, ODI, the volume of blood loss, operation time, hospital stay, CRP, ESR, Cobb's angle and bone fusion time between the two groups were compared using the Student's t-test. Gender, neurological function by Frankel and diseases location site were compared by chi-square $(x 2)$ test. A P value of less than 0.05 was considered to be statistically significant.

\section{Results}

All 34 patients, 18 from group A and 16 from group B were followed-up for 3 years. The surgical incisions in both groups healed without chronic infection, fistula formation, and there was no recurrence of TB from both groups. No complications related to instrumentation occurred from both groups. One patient from group $B$ developed pneumonia. however, the patient was treated with antibiotics and antiinflammatory drugs. The average operation time for the group $A$ was shorter than that of group $B, 144.2 \pm$ 16.5 mins vs $170.3 \pm 25.0$ mins $(p=0.001)$ respectively. Average intraoperative blood loss for group $A$ was less than that of group B, $502.8 \pm 151.9 \mathrm{mls}$ vs $742.5 \pm 143.2 \mathrm{mls}(\mathrm{p} \otimes 0.05)$ respectively. No significant difference found on the average number of hospitals stay between group $A$ and group $B, 39.4$ \pm 11.9 days and $29.2 \pm 6.5$ days $(p=0.167)$ respectively. Table 2 .

The mean cobb's angle between group A versus group $B$; preoperative was $23.8 \pm 6.5^{0}$ vs $22.2 \pm 9.2^{0}$ ( $p=$ $0.6)$, immediate post operatively was $8.0 \pm 3.5^{0}$ vs $8.3 \pm 5.7^{0}(p=0.847)$ and at final follow-up was $8.9 \pm$ $3.1^{0}$ vs $9.2 \pm 5.9^{0}(p=0.866)$. Correction rate was $15.7 \pm 3.8^{0}$ vs $13.9 \pm 5.5^{0}(p=0.285)$ and loss of correction at final follow-up was $1.2 \pm 0.7^{0}$ vs $1.1 \pm 0.7(p=0.817)$ respectively. Table 3 .

No subsidence of TMCs were observed after surgery in both groups. All TMCS undergo thoroughly fusion, there was no significant difference between the two groups. The mean fusion time for the group $A$ vs group $B$ was $8.4 \pm 2.2$ months vs $8.6 \pm 2.2$ months $(p=0.82)$ respectively.

The average ESR for group A vs group B was; preoperative $42.6 \pm 19.0 \mathrm{~mm} / \mathrm{h}$ vs $51.1 \pm 23.8 \mathrm{~mm} / \mathrm{h}(\mathrm{p}=$ $0.256), 3$ months postoperative $15.7 \pm 5.6 \mathrm{~mm} / \mathrm{h}$ vs $15.8 \pm 8 \mathrm{~mm} / \mathrm{h}(\mathrm{p}=0.967)$ and $6.2 \pm 2.7 \mathrm{~mm} / \mathrm{h}$ vs 5.8 $\pm 2.8(p=0.577)$ at final follow-up respectively. The average CRP for group A vs group B was; preoperative $20.5 \pm 28.7 \mathrm{mg} / \mathrm{l}$ vs $21.6 \pm 13.7 \mathrm{mg} / \mathrm{l}(\mathrm{p}=0.894), 3$ months postoperative $1.9 \pm 0.9 \mathrm{mg} / \mathrm{l}$ vs $2.2 \pm 1.2 \mathrm{mg} / \mathrm{l}(p=0.394)$ and $1.1 \pm 0.5 \mathrm{mg} / \mathrm{l}$ vs $1.1 \pm 0.6 \mathrm{mg} / \mathrm{l}(\mathrm{p}=0.753)$ at final follow-up respectively. Table 4.

ODI for group A vs group B was; preoperative $40 \pm 17 \%$ vs $44.4 \pm 14 \%(p=0.43)$ and $14.1 \pm 1.1 \%$ vs 15.2 $\pm 5.1 \%(p=0.672)$ at final follow-up respectively. VAS for group A and group B was; preoperative $7.3 \pm 1$ 
vs $7.2 \pm 1.8(p=0.87)$ and $0.61 \pm 0.6$ vs $0.62 \pm 0.6(p=0.948)$ at final follow-up. Table 5 .

Neurological recovery as assessed by Frankel scale for group A, 1 patient for grade B recovered to grade $D, 5$ grade $C$ patients 1 patient recovered to grade $D$ and 4 patients recovered to grade $E$, and 12 grade $D$ patients all recovered to grade $E$, while for group $B, 2$ patients for grade $B$, one recovered to grade $D$ and one grade $E, 7$ grade $C$ patient, 2 patients recovered to grade $D$ and 5 patients to grade $E \otimes 7$ grade $D$ patients all recovered to grade $\mathrm{E}$. Table 6 .

\section{Discussion}

The prevalence of spinal TB has recently increased because of the ongoing increase in human immunodeficiency virus (HIV) epidemic and drug resistance. The surgical intervention combined with anti-TB chemotherapy can secure good outcomes and treat paraplegia. The purpose of spinal surgery involves the eradication of the lesion, decompression of the nerves, restoration of spinal stability and correction of spinal deformity(14-17). currently, short- and long-segment fixation methods are commonly used during the surgical treatment of spinal $\operatorname{TB}(18,19)$. The merits of the two fixation methods include regaining the normal structure of the spine and maintaining the correction. Demerits include decreased mobility and loss of function of the normal motor unit which accelerates ASD. Moreover, long segments fixation results in more concentrated stress and exert greater forces on adjacent segments. These effects accelerate adjacent segment degeneration, which leads to lower back pain, pseudarthrosis and implant failure(20-22).

Autograft bones are better alternative materials for reconstructing spine than allograft bone; nevertheless, donor site complications as reported from the literature is as high as $10 \%$, chronic donor site pain is as high as $40 \%$. Moreover, the incidence of fracture for both allograft and autograft during surgery and after surgery is commonly reported(23-28). In both groups, we used TMCs filled with autograft or allograft followed by instrumentation for augmentation. This provide some advantages, including instant anterior stability, an estimation of the intervertebral disc height, and prevention of bone graft taken outside the surgical site(29-31)!

The results of our study show that contrary to the short-segment fixation group, the mono-segment fixation group had shorter operative time and less intraoperative blood loss this is because the fixation was only done on the affected motor unit. Also, the incision length in mono-segment fixation was relatively shorter compared to that of short-segment fixation. Our results are similar to those reported in the literature by Liang et al(18), and Liu et al(32). Nevertheless, there was no substantial difference between the two groups with respect to the number of hospital stays, VAS, ODI, neurological recovery as assessed by Frankel impairment scale, ESR, CRP and fusion time. These results are similar to those reported in the literature by Zhang et al(33) and wang et al(7). Furthermore, there was no significant difference between the two groups with respect to curve correction, mean postoperative correction in Cobb's angle, and loss of correction at 3 years after surgery. Also, loss of correction at the final follow-up was $<3^{0}$ in both groups, these results are similar to those reported in the literature by Mukhtar et al(34) 
Wang et al (35) and liu et al (32). This study also shows that both posterior mono-segment fixation and short-segment fixation with TMCs used in the treatment of mono-segmental lumbar TB can safely and effectively reconstruct the lumbar spine and maintain the correction of the deformity for an extended period. This is similar to the application of anterior debridement and interbody graft followed by posterior fixation using autologous iliac bone graft as previously reported by Talu et al(36) Jain et al(37) and Hirakawa et al(38).

As reported from the literature $1 / 3-2 / 3$ of the vertebral height is larger enough to hold the standard pedicle screw. Moreover, the diseased vertebrae with TB displays a sclerotic cortex with higher bone mineral density than normal vertebrae. This gives a tough holding force on the vertebrae with tuberculous lesions. Hence, we can adopt mono-segment fixation and avoid fixing across the normal intervertebral space $(8,16)$.

Even though the mechanical strength of mono-segment fixation is relatively less strong compared to that of short-segment and long-segment fixation. We found that in some indications we can apply monosegment fixation to treat lumbar TB and obtain the same results as in short-segment fixation. These indications are the same as previously reported by Liang et al(18) as follows: (1) Both endplates of the diseased vertebrae shall be intact to provide a secure host bed for graft fusion. (2) kyphosis deformity should be $<60^{\circ}$. (3) Intact pedicles and free from TB erosion. (4) The disease is confined to one segment or two adjacent segments. (5) The paraspinal abscess is limited and remains local. The mono-segment fixation method is contraindicated to the following cases; (1) patients with severe kyphosis deformity $>60^{\circ}$. (2) aged or osteoporotic patients. (3) patients with extensive paraspinal abscess.

Some potential shortcomings of this study should be considered. The study was retrospective in nature with small sample size. However, our results were similar to what has been reported by previous studies. To confirm the validity and utility of these approaches, there is a need to conduct prospective studies with a larger number of cases. Additionally, it would be useful to compare the outcome of combined anteriorposterior approach and mono-segment fixation through posterior-only approach.

\section{Conclusion}

Under precise conditions: mono-segment fixation method, debridement, interbody fusion with TMCs, and posterior instrumentation can effectively reconstruct the spine, maintain stability and correct kyphosis deformity similar to short-segment fixation method. Also, it can relieve pain and improve neurological symptoms. When used in combination with anti-TB chemotherapy in the treatment of mono-segmental lumbar TB via a single stage posterior-only approach. However, the present study is a retrospective singlecenter study with small sample size. Therefore, we recommend multicenter, large-sample size, prospective randomized controlled studies to be carried out in the future to improve the level of evidence-based medicine and support our findings.

\section{Abbreviations}


$T M C s=$ Titanium mesh cages, $M L s=$ milliliter, $T B=$ Tuberculosis, $H I V=$ human immunodeficiency virus, $A S D=$ adjacent segmental disease, $H R E Z=$ Isoniazid, Rifampicin, Ethambutol Pyrazinamide. VAS = Visual analogue scale, $O D I=$ Oswestry disability index, $E S R=$ Erythrocyte sedimentation rate, $C R P=$ C-reactive protein, $C T=$ Computed tomography, $M R I=$ Magnetic resonance imaging.

\section{Declarations}

\section{Ethical approval and consent to participate:}

The study protocol was approved by the Ethics Committee of the Xiangya first Hospital of Central South University.

\section{Consent for publication:}

"Not applicable"

\section{Availability of data and material:}

"All datasets analyzed during this study are included in this article given as supplementary information file"

\section{Competing Interest囚}

The authors declare that they have no competing interest.

\section{Funding:}

No fund received during the preparation of this work

\section{Authors contribution:}

$H Z Q$, gave the idea and designed the study, MDR and YXW collected the data, analyzed the data and wrote the paper. All authors read and approved the final manuscript.

\section{Acknowledgements $\rrbracket$}

The authors cordially appreciate the assistance from the working staff of the medical record department of Xiangya first hospital for providing the data whenever needed. Special thanks to Dr. DuyuXuan for translating some Chinese material into English. 


\section{Authors information}

Hongqi Zhang: Is currently head of department of spine surgery of Xiangya hospital of Central South University.

Daudi Romani Manini: Is currently a $3^{\text {rd }}$ year resident in spine department ofXiangya hospital of Central South University.

YuXiangWang; Is currently a spinal surgeon, in the department of spinesurgery of Xiangya hospital of Central South University.

\section{References}

1.Chen $\mathrm{CH}$, Chen YM, Lee CW, al e. Early diagnosis of spinal tuberculosis. Journal of the Formosan Medical Association = Taiwan yi zhi. 2016;115(10):825-36.

2.Sharma A, Chhabra HS, Chabra T, Mahajan R, Batra S, Sangondimath G. Demographics of tuberculosis of spine and factors affecting neurological improvement in patients suffering from tuberculosis of spine: a retrospective analysis of 312 cases. Spinal cord. 2017;55(1):59-63.

3.Zhang HQ, Li M, Wang YX, Tang MX, Guo CF, Liu SH, et al. Minimum 5-year follow-up outcomes for Comparison between Titanium mesh cage and allogeneic bone graft to Reconstruct Anterior Column through Posterior Approach for the Surgical treatment of Thoracolumbar Spinal Tuberculosis with Kyphosis. World neurosurgery. 2019.

4.Yin XH, He BR, Liu ZK, Hao DJ. The clinical outcomes and surgical strategy for cervical spine tuberculosis: A retrospective study in 78 cases. Medicine. 2018;97(27):e11401.

5.Huang Y, Lin J, Chen X, Lin J, Lin Y, Zhang H. Correction to a posterior versus anterior debridement in combination with bone graft and internal fixation for lumbar and thoracic tuberculosis. Journal of orthopaedic surgery and research. 2018;13(1):103.

6. Hassan K, Elmorshidy E. Anterior versus posterior approach in surgical treatment of tuberculous spondylodiscitis of thoracic and lumbar spine. European spine journal: official publication of the European Spine Society, the European Spinal Deformity Society, and the European Section of the Cervical Spine Research Society. 2016;25(4):1056-63.

7.Wang Z, Yuan H, Geng G, Shi J, Jin W. Posterior mono-segmental fixation, combined with anterior debridement and strut graft, for treatment of the mono-segmental lumbar spine tuberculosis. International orthopaedics. 2012;36(2):325-9.

8.Xu Z, Wang X, Wu P, Pang X, Luo C, Zhang P, et al. Surgical treatment for mono-segmental lumbar tuberculosis by single-stage posterior debridement, compact bone grafting and posterior single-segment 
fi xation. Injury. 2015;46(7):1311-6.

9.Wang Z, Wu Q, Geng G. Anterior debridement and bone grafting with posterior single-segment internal fixation for the treatment of mono-segmental spinal tuberculosis. Injury. 2013;44(2):253-7.

10.Shi JD, Wang Q, Wang ZL. Primary issues in the selection of surgical procedures for thoracic and lumbar spinal tuberculosis. Orthopaedic surgery. 2014;6(4):259-68.

11.Weinhoffer SL, Guyer RD, Herbert M, Griffith SL. Intradiscal pressure measurements above an instrumented fusion. A cadaveric study. Spine. 1995;20(5):526-31.

12.Moon MS, Woo YK, Lee KS, Ha KY, Kim SS, Sun DH. Posterior instrumentation and anterior interbody fusion for tuberculous kyphosis of dorsal and lumbar spines. Spine. 1995;20(17):1910-6.

13.Rajasekaran S, Vijay K, Shetty AP. Single-stage closing-opening wedge osteotomy of spine to correct severe post-tubercular kyphotic deformities of the spine: a 3-year follow-up of 17 patients. European spine journal: official publication of the European Spine Society, the European Spinal Deformity Society, and the European Section of the Cervical Spine Research Society. 2010;19(4):583-92.

14.Jiang T, Zhao J, He M, Wang K, Fowdur M, Wu Y. Outcomes and Treatment of Lumbosacral Spinal Tuberculosis: A Retrospective Study of 53 Patients. PloS one. 2015;10(6):e0130185.

15.Rajasekaran S, Kanna RM, Shetty AP. History of spine surgery for tuberculous spondylodiscitis. Der Unfallchirurg. 2015;118 Suppl 1:19-27.

16.Jin W, Wang Q, Wang Z, Geng G. Complete debridement for treatment of thoracolumbar spinal tuberculosis: a clinical curative effect observation. The spine journal: official journal of the North American Spine Society. 2014;14(6):964-70.

17.Abdul-Jabbar A, Takemoto S, Weber MH, Hu SS, Mummaneni PV, Deviren V, et al. Surgical site infection in spinal surgery: description of surgical and patient-based risk factors for postoperative infection using administrative claims data. Spine. 2012;37(15):1340-5.

18.Liang Q, Wang Q, Sun G, Ma W, Shi J, Jin W, et al. Five-year outcomes of posterior affected-vertebrae fixation in lumbar tuberculosis patients. Journal of orthopaedic surgery and research. 2018;13(1):210.

19.Gong K, Wang Z, Luo Z. Single-stage posterior debridement and transforaminal lumbar interbody fusion with autogenous bone grafting and posterior instrumentation in the surgical management of lumbar tuberculosis. Archives of orthopaedic and trauma surgery. 2011;131(2):217-23.

20.Hilibrand AS, Robbins M. Adjacent segment degeneration and adjacent segment disease: the consequences of spinal fusion? The spine journal: official journal of the North American Spine Society. 2004;4(6 Suppl):190s-4s. 
21.Min JH, Jang JS, Jung B, Lee HY, Choi WC, Shim CS, et al. The clinical characteristics and risk factors for the adjacent segment degeneration in instrumented lumbar fusion. Journal of spinal disorders \& techniques. 2008;21(5):305-9.

22.Levin DA, Hale JJ, Bendo JA. Adjacent segment degeneration following spinal fusion for degenerative disc disease. Bulletin of the NYU hospital for joint diseases. 2007;65(1):29-36.

23.Arrington ED, Smith WJ, Chambers HG, Bucknell AL, Davino NA. Complications of iliac crest bone graft harvesting. Clinical orthopaedics and related research. 1996(329):300-9.

24.Dimitriou R, Mataliotakis GI, Angoules AG, Kanakaris NK, Giannoudis PV. Complications following autologous bone graft harvesting from the iliac crest and using the RIA: a systematic review. Injury. 2011;42 Suppl 2:S3-15.

25.Dawson J, Kiner D, Gardner W, 2nd, Swafford R, Nowotarski PJ. The reamer-irrigator-aspirator as a device for harvesting bone graft compared with iliac crest bone graft: union rates and complications. Journal of orthopaedic trauma. 2014;28(10):584-90.

26.Eck KR, Lenke LG, Bridwell KH, Gilula LA, Lashgari CJ, Riew KD. Radiographic assessment of anterior titanium mesh cages. Journal of spinal disorders. 2000;13(6):501-9; discussion 10.

27.Schnee CL, Freese A, Weil RJ, Marcotte PJ. Analysis of harvest morbidity and radiographic outcome using autograft for anterior cervical fusion. Spine. 1997;22(19):2222-7.

28.Prakash SK, Mukerji N, Nath FP. Is tutobone an efficient alternative to other implants used in anterior cervical discectomy and fusion surgeries? British journal of neurosurgery. 2017;31(3):340-4.

29.Korovessis P, Petsinis G, Koureas G, lliopoulos P, Zacharatos S. Anterior surgery with insertion of titanium mesh cage and posterior instrumented fusion performed sequentially on the same day under one anesthesia for septic spondylitis of thoracolumbar spine: is the use of titanium mesh cages safe? Spine. 2006;31(9):1014-9.

30.Zhang H, Guo Q, Wang Y, Guo C, Tang M. The efficiency of the posterior-only approach using shaped titanium mesh cage for the surgical treatment of spine tuberculosis in children: A preliminary study. Journal of orthopaedic surgery (Hong Kong). 2018;26(3):2309499018806684.

31.Zhang H, Zeng K, Yin X, Huang J, Tang M, Guo C. Debridement, internal fixation, and reconstruction using titanium mesh for the surgical treatment of thoracic and lumbar spinal tuberculosis via a posterioronly approach: a 4-year follow-up of 28 patients. Journal of orthopaedic surgery and research. 2015;10(1):150.

32.Liu Z, Zhang P, Zeng H, Xu Z, Wang XJIO. A comparative study of single-stage transpedicular debridement, fusion, and posterior long-segment versus short-segment fixation for the treatment of 
thoracolumbar spinal tuberculosis in adults: minimum five year follow-up outcomes. 2018;42(8):188390 .

33.Zhang H, Zeng K, Yin X, Huang J, Tang M, Guo C. Debridement, internal fixation, and reconstruction using titanium mesh for the surgical treatment of thoracic and lumbar spinal tuberculosis via a posterioronly approach: a 4-year follow-up of 28 patients. Journal of orthopaedic surgery and research. 2015;10:150.

34.Mukhtar AM, Farghaly MM, Ahmed SH. Surgical treatment of thoracic and lumbar tuberculosis by anterior interbody fusion and posterior instrumentation. Medical principles and practice: international journal of the Kuwait University, Health Science Centre. 2003;12(2):92-6.

35.Wang X, Pang X, Wu P, Luo C, Shen X. One-stage anterior debridement, bone grafting and posterior instrumentation vs. single posterior debridement, bone grafting, and instrumentation for the treatment of thoracic and lumbar spinal tuberculosis. European spine journal: official publication of the European Spine Society, the European Spinal Deformity Society, and the European Section of the Cervical Spine Research Society. 2014;23(4):830-7.

36.Talu U, Gogus A, Ozturk C, Hamzaoglu A, Domanic U. The role of posterior instrumentation and fusion after anterior radical debridement and fusion in the surgical treatment of spinal tuberculosis: experience of 127 cases. Journal of spinal disorders \& techniques. 2006;19(8):554-9.

37.Jain AK, Dhammi IK, Prashad B, Sinha S, Mishra P. Simultaneous anterior decompression and posterior instrumentation of the tuberculous spine using an anterolateral extrapleural approach. The Journal of bone and joint surgery British volume. 2008;90(11):1477-81.

38. Hirakawa A, Miyamoto K, Ohno Y, Hioki A, Ogawa H, Nishimoto H, et al. Two-stage (posterior and anterior) surgical treatment of spinal osteomyelitis due to atypical mycobacteria and associated thoracolumbar kyphoscoliosis in a nonimmunocompromised patient. Spine. 2008;33(7):E221-4.

\section{Tables}

Table 1 Patients' characteristics and preoperative variables. 


\begin{tabular}{llll}
\hline Entry & group (A) & group (B) & P value \\
\hline Patients & 18 & 16 & \\
Gender (f/m) & $8 / 10$ & $8 / 8$ & 0.746 \\
Aged ( \pm s years) & $41.8 \pm 12.8$ & $48.9 \pm 14.6$ & 0.144 \\
Disease duration ( \pm s) months) & & & \\
Disease site & $7.3 \pm 1.7$ & $7.0 \pm 1.6$ & 0.567 \\
L1-2 & & & 0.213 \\
L2-3 & 2 & 4 & \\
L3-4 & 4 & 3 & \\
L4-5 & 5 & 2 & \\
L5-S1 & 4 & 7 & \\
Cobb's angle ( \pm s ${ }^{0}$ ) & 3 & 0 & \\
ESR ( $\pm \mathrm{s} \mathrm{mm} / \mathrm{h})$ & $23.8 \pm 6.5$ & $22.2 \pm 9.2$ & 0.6 \\
CRP ( \pm s mg/l) & $42.6 \pm 19$ & $51.1 \pm 23.8$ & 0.256 \\
& $20.5 \pm 28.7$ & $21.6 \pm 13.7$ & 0.894 \\
\hline
\end{tabular}

$\mathrm{L}=$ lumbar vertebra, $( \pm \mathrm{s})=$ mean and standard deviation $\square \mathrm{S} 1=$ sacral vertebra number one.

Table 2ם The average operation time, blood loss and hospital stay for group A and B expressed in mean and standard deviation!

\begin{tabular}{lllll}
\hline Group & $\mathrm{n}$ & Operation time (minutes) & Blood loss (mls) & Hospital stay (days) \\
\hline A & 18 & $144.2 \pm 16.5$ & $502.78 \pm 151.92$ & $39.4 \pm 11.9$ \\
B & 16 & $170.3 \pm 25.0$ & $742.5 \pm 143.19$ & $29.2 \pm 6.5$ \\
P value & & 0.001 & $<0.05$ & 0.167 \\
\hline
\end{tabular}

mls $=$ milliliter $\square \mathrm{n}=$ number of patients

Table 3, Cobb angle (in degree) for group A and group B expressed as mean and standard deviation.

\begin{tabular}{lllllll}
\hline Group & $\mathrm{n}$ & $\begin{array}{l}\text { Pre op cobb } \\
\text { angle }\end{array}$ & $\begin{array}{l}\text { Immediate post op cobb } \\
\text { angle }\end{array}$ & $\begin{array}{l}\text { Final follow-up cobb } \\
\text { angle }\end{array}$ & $\begin{array}{l}\text { Correction } \\
\text { rate }\end{array}$ & $\begin{array}{l}\text { Loss of } \\
\text { correction at ffu. }\end{array}$ \\
\hline A & 18 & $23.8 \pm 6.5$ & $7.99 \pm 3.54$ & $8.9 \pm 3.1$ & $15.7 \pm 3.8$ & $1.2 \pm 0.7$ \\
$\mathrm{~B}$ & 16 & $22.2 \pm 9.2$ & $8.30 \pm 5.68$ & $9.2 \pm 5.9$ & $13.9 \pm 5.5$ & $1.1 \pm 0.9$ \\
$\mathrm{P}$ & & 0.6 & 0.847 & 0.866 & 0.285 & 0.817 \\
value & & & & & \\
\hline
\end{tabular}

$\mathrm{ffu}=$ final follow-up $\mathrm{n}=$ number of patients.

Table $4 \square$ The values of ESR and CRP between group A and B expressed in mean and standard deviation. 


\begin{tabular}{llllllll}
\hline Group & $\mathrm{n}$ & \multicolumn{2}{l}{ Pre op } & & \multicolumn{2}{l}{ 3 months post op } & \multicolumn{2}{l}{ 3 years post op } \\
\cline { 3 - 7 } & & ESR & CRP & ESR & CRP & ESR & CRP \\
\hline A & 18 & $42.6 \pm 19.0$ & $20.5 \pm 28.7$ & $15.7 \pm 5.6$ & $1.9 \pm 0.9$ & $6.2 \pm 2.7$ & $1.1 \pm 0.5$ \\
B & 16 & $51.1 \pm 23.8$ & $21.6 \pm 13.7$ & $15.8 \pm 8$ & $2.2 \pm 1.9$ & $5.8 \pm 2.8$ & $1.1 \pm 0.6$ \\
P value & & 0.256 & 0.894 & 0.967 & 0.394 & 0.577 & 0.753 \\
\hline
\end{tabular}

$\mathrm{ESR}=(\mathrm{mm} / \mathrm{h}), \mathrm{CRP}=(\mathrm{mg} / \mathrm{l})$.

Table 5. visual analogue score and percentage Oswestry disability index score. All values are in expressed in mean and standard deviation]

\begin{tabular}{llllll}
\hline & & \multicolumn{2}{c}{ preoperative } & \multicolumn{2}{l}{ 3 years postoperative } \\
\cline { 3 - 6 } Group & $\mathrm{n}$ & VAS & ODI & VAS & ODI \\
\hline A & 18 & $7.3 \pm 1$ & $40 \pm 17$ & $0.61 \pm 0.6$ & $14.1 \pm 1.1$ \\
B & 16 & $7.2 \pm 1.8$ & $44.4 \pm 14$ & $0.62 \pm 0.6$ & $15.2 \pm 5.1$ \\
P & & 0.87 & 0.43 & 0.95 & 0.672 \\
\hline
\end{tabular}

Table 6, pre-operative and post-operative Frankel grade between the two groups.

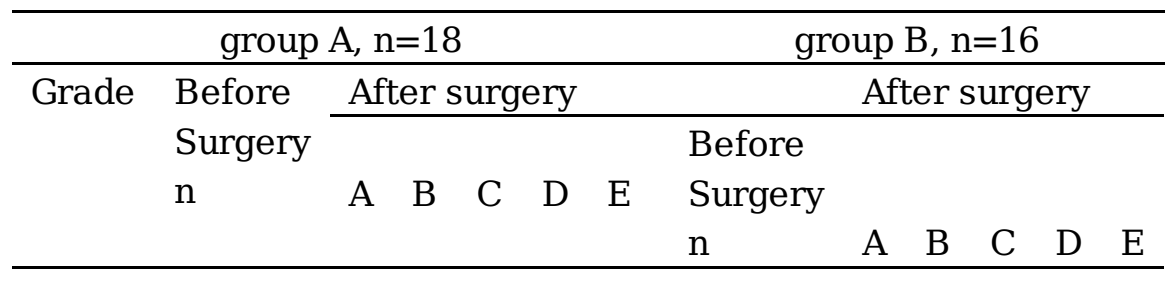

\begin{tabular}{lllllll} 
A & & & & & & \\
B & 1 & 1 & & 2 & 1 & 1 \\
C & 5 & 1 & 4 & 7 & 2 & 5 \\
D & 12 & & & & & \\
E & & & 12 & 7 & & 7 \\
\hline
\end{tabular}

\section{Figures}



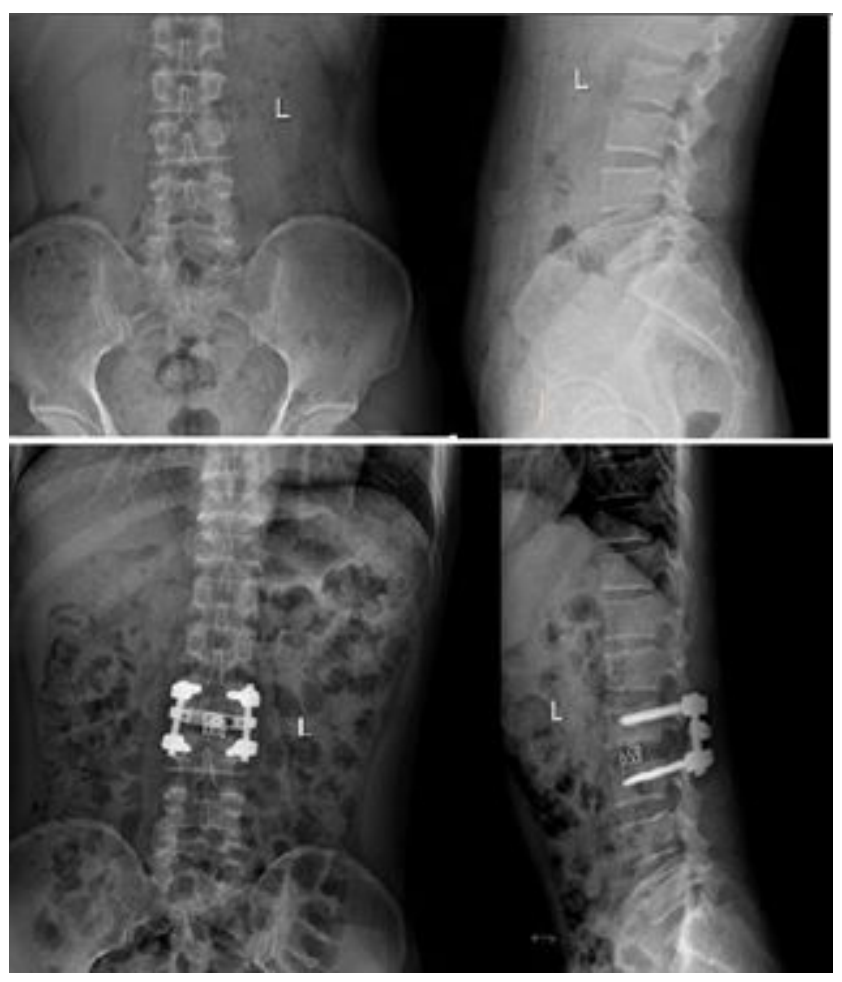

\section{Figure 1}

A 49 years old male with lumbar spinal tuberculosis lesion at I2/I3 who underwent mono-segment fixation. a: Preoperative anteroposterior view; b: preoperative lateral view; c: postoperative anteroposterior view; d: postoperative lateral view.

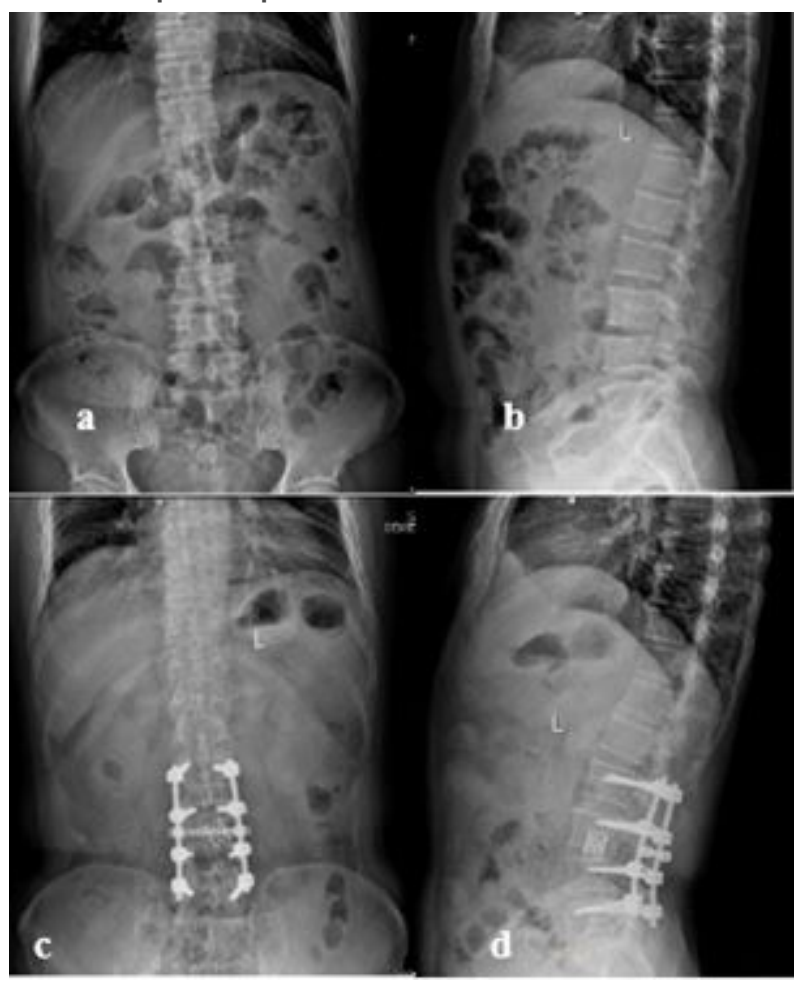

Figure 2 
A 54 years old male with lumbar spinal tuberculosis lesion at I3/I4 who underwent short-segment fixation. a: Preoperative anteroposterior view; b: preoperative lateral view; c: postoperative anteroposterior view; d: postoperative lateral view. 